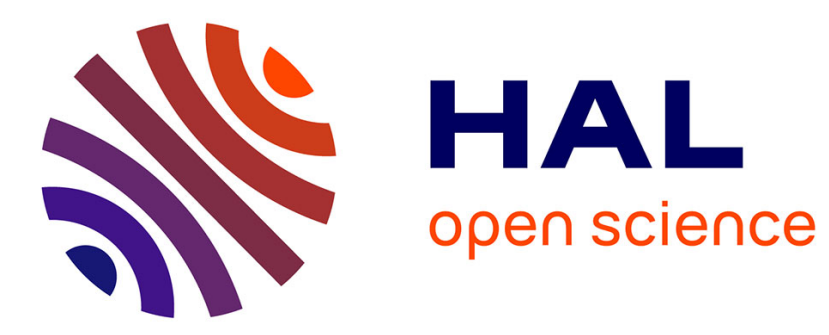

\title{
A Generic Method for Robust Performance Analysis of Aircraft DC Power Systems
}

Matthieu Sautreuil, Nicolas Retière, Delphine Riu, Olivier Sename

\section{To cite this version:}

Matthieu Sautreuil, Nicolas Retière, Delphine Riu, Olivier Sename. A Generic Method for Robust Performance Analysis of Aircraft DC Power Systems. IECON 2008 - 34th Annual Conference of the IEEE Industrial Electronics Society, Nov 2008, Orlando, Floride, United States. hal-00339301

\section{HAL Id: hal-00339301 https://hal.science/hal-00339301}

Submitted on 17 Nov 2008

HAL is a multi-disciplinary open access archive for the deposit and dissemination of scientific research documents, whether they are published or not. The documents may come from teaching and research institutions in France or abroad, or from public or private research centers.
L'archive ouverte pluridisciplinaire HAL, est destinée au dépôt et à la diffusion de documents scientifiques de niveau recherche, publiés ou non, émanant des établissements d'enseignement et de recherche français ou étrangers, des laboratoires publics ou privés. 


\section{A Generic Method for Robust Performance Analysis of Aircraft DC Power Systems}

\author{
M. Sautreuil, N. Retière, D. Riu \\ G2ELab - UMR 5269 \\ 38402 Saint-Martin-d'Hères Cedex - France \\ Email :(sautreuil,retiere,riu)@g2elab.inpg.fr
}

\begin{abstract}
The recent evolution of aircraft power networks makes new design study necessary for solving key issues such as optimal efficiency, reliability, adaptability and performances. Indeed, DC power systems are subject to strong dynamic interactions between the source and the loads. In this paper, the need for a new design method of the power network is explained, and the authors propose to use a robust performance analysis method. The first main result concerns the analysis of the robustness of a classical aircraft DC source where the parameters of the DC bus are unknown. The second one shows the efficiency of the method to evaluate the potential gain in weight from a change in the performance specifications at the system level.
\end{abstract}

\section{INTRODUCTION}

At the end of the $19^{\text {th }}$ century, DC electrical systems were progressively replaced by $\mathrm{AC}$ distribution for flexibility reasons. With the development of power electronics and the generalization of electricity as an energetic vector, DC power systems are getting more and more used. Then, reactive energy management is not anymore necessary and AC/DC conversion stages are suppressed. This allows improvements in system efficiency, reliability and maintenance costs [1,2]. Typical applications of DC systems include telecommunications, ships, spacecrafts and "More Electric" vehicles $[1,3,4,5]$. For aircraft applications, the power distribution is moving from $400 \mathrm{~Hz} / 115 \mathrm{VAC}$ to HVDC. European aircraft manufacturers initiated this change with the "Power Optimized Aircraft" European project [6] followed by the current "More Open Electrical Technologies" project. The work presented in this paper is part of the latter.

MOET project [8] is focused on several aspects. One is the standardization of power electronics devices for aircraft applications. A second one is the integration of these devices in the power system. A classical approach for subsystems integration is to impose strict standards to the devices suppliers in order to guarantee that performance requirements will be met at the system level. The standards at the system level for aircraft DC networks are given in Fig. 1. They are generally defined by the aircraft manufacturer. If these standards are not respected when the integration is carried out, some of the devices should be re-designed by their suppliers. This may lead to a long design process, especially for a DC network design where dynamic interactions between the source and the loads may be strong [2]. It is a crucial point because the aircraft development program can be

\author{
O. Sename \\ Gipsa-lab - UMR 5216 \\ 38402 Saint-Martin-d'Hères Cedex - France \\ Email :olivier.sename@gipsa-lab.inpg.fr
}

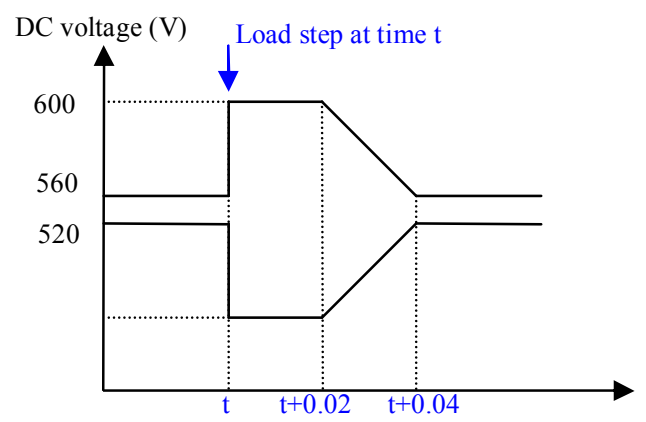

Fig. 1: Assigned transient envelop after a load step at Point Of Regulation (POR)

delayed, which could be very costly for the aircraft manufacturer. The authors propose to solve this point by a new approach based on robustness. It means that the devices will be designed so that they could withstand changes in their operating environment once integrated with minimal loss of performance. Only dynamic performances will be addressed in this paper even if energetic or harmonic issues could certainly be included in a general robustness approach. .

Another key design issue is that devices are designed for given performance requirements at the system level (Fig. 1). The question is then to know if the standards are suitable for the system optimization. In the case of "More Electric" aircrafts, the optimization addresses the issue of reducing the weight. The authors will show that the robustness indicators could be used for that purpose.

The robust performance analysis performed in this article will be applied to a DC power channel described in section II. In section III, the linear models necessary for the analysis are developed using a simple identification-based approach. Section IV explains the robust performance analysis from a theoretical point of view and its application to the studied power channel [9]. In section $\mathrm{V}$, the authors focus on the design results which can be achieved by the analysis. A particular attention will be paid to the influence of the source control. In section VI, the robust performance analysis is shown to be efficient for giving indicators to the network designer for the optimization of the system weight.

\section{POWER CHANNEL DESCRIPTION}

The DC power channel is constituted by (Fig.2):

- a wounded rotor alternator which provides the energy to the power channel. The speed loop is 
assumed to be ideal. The generator is connected to a 18-pulses Autotransformer Rectifier Unit (ATRU)

- a DC filter

- a Motor Controlled Unit (MCU) constituted by a voltage source inverter and a Permanent Magnet Synchronous Machine (PMSM). The motor drives a mechanical load, for instance a fuel pump.

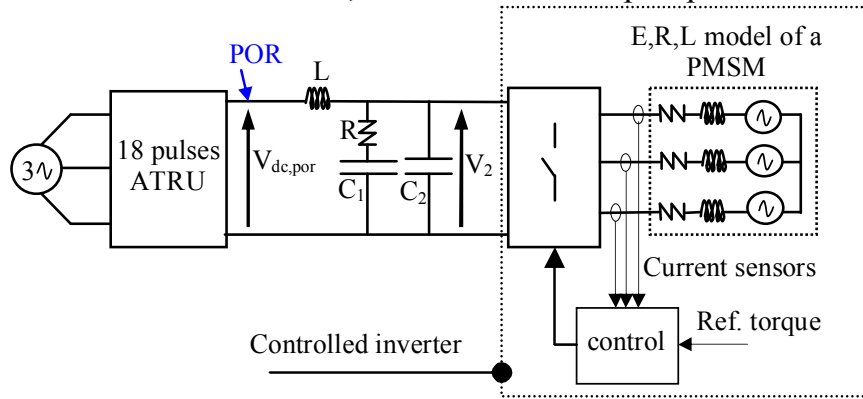

Fig. 2: Power channel description

The alternator excitation voltage is regulated through a PI controller (Fig. 3) and the stator frequency is assumed to be maintained at $400 \mathrm{~Hz}$. The generator supplies a nine phase autotransformer connected to three diode bridges. It is a classical structure for aircraft applications. The interphase inductors limit circulation currents between the rectifiers. The nominal voltage on the DC side is $540 \mathrm{Vdc}$ for a $60 \mathrm{~kW}$ load.

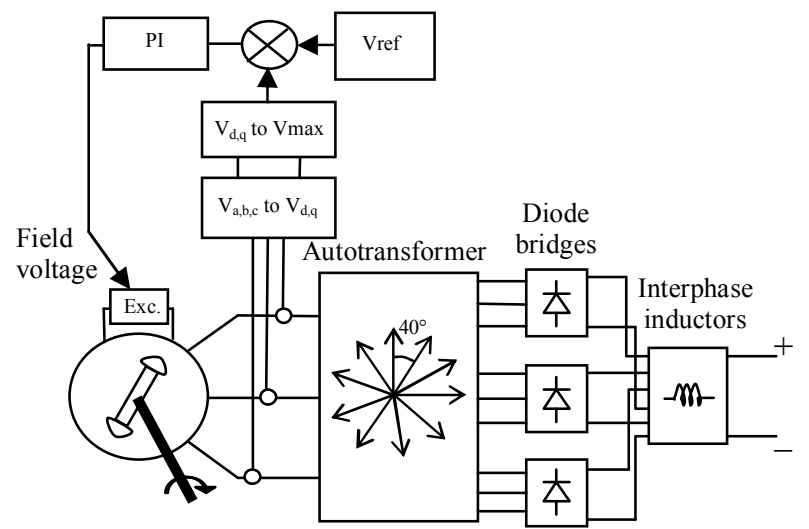

Fig. 3: Detailed source structure

The speed control loop of the PMSM (Fig. 4) is assumed to be ideal. Then, the AC side variables have a constant frequency $(1000 \mathrm{~Hz})$ and the machine can be modeled by its equivalent (R,L,E) model (constant flux and electrical pulsation).

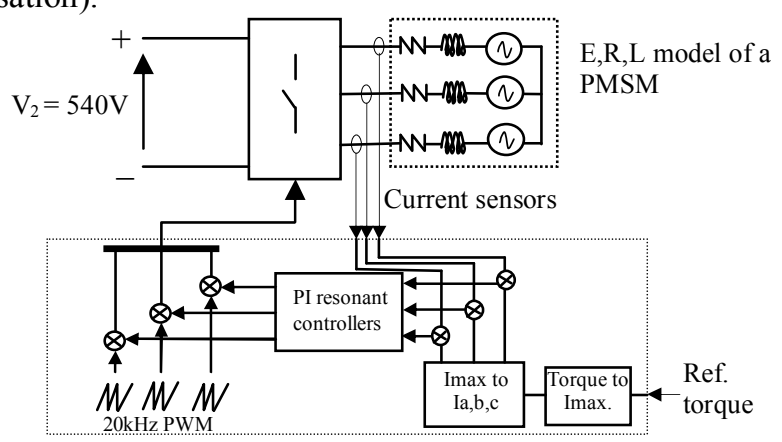

Fig. 4: Detailed load structure
The measured currents (Fig. 4) are controlled with a PI resonant controller, tuned at $1000 \mathrm{~Hz}$. A $20 \mathrm{kHz}-$ Pulse Width Modulator delivers the commutation orders to the switches of the inverter.

\section{SMALL SIGNAL MODELING OF THE POWER CHANNEL}

A Saber model of the power channel has been implemented. It will be used as a reference, in particular to obtain and validate the small-signal modeling required by the robust performance analysis.

\section{A. Source and load modeling}

Source and load are modeled using a frequency domain identification approach. The main advantage of this approach is its simplicity. It enables to identify the average behavior of the state variables. The models are then valid only for frequencies lower than half of the switching frequencies of the power electronic converters. To perform this frequency domain identification, a variable-frequency and small-signal sinus excitation is injected at the input of the load and at the output of the source. Before this injection, both load and source were operating at their steady-state nominal point. Resulting current and voltage are finally measured to compute the impedance over a large range of frequencies.

\section{Load modeling}

Fig.5 shows that the MCU input gain and phase are constant for frequencies lower than half of the PWM frequency $(10 \mathrm{kHz})$. Because phase is $-180 \mathrm{deg}$, it is a negative resistance behavior. For small-signal excitation the MCU load can then be identified as a constant power load.

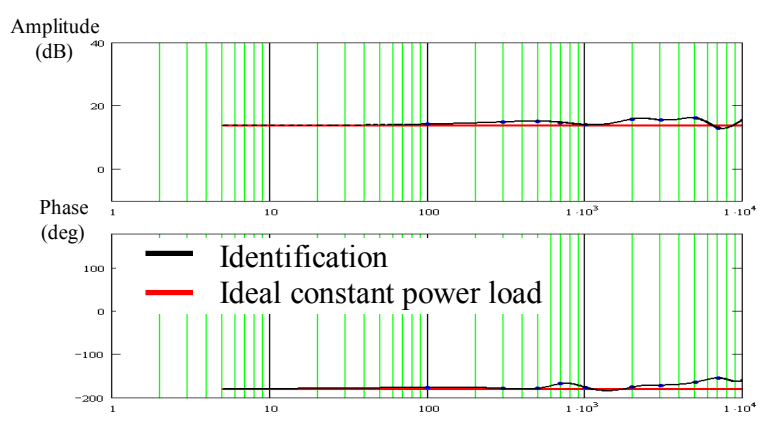

Fig. 5: Frequency domain identification of the $60 \mathrm{~kW}$ MCU

\section{Source modeling}

The source (alternator + ATRU) is identified in two cases:

- case 1: the alternator is assumed to be ideally controlled. It means the AC voltage is assumed to be maintained at its nominal value. This case gives then the best performances achievable by any AC source control. In the next sections, this study case is called "ideal control" case.

- case 2: the generator PI control is taken into account.

Fig. 6 shows the identification results when an ideal AC source is considered (case 1). The ATRU is fed by a $400 \mathrm{~Hz}$ 
source, then the switching frequency of the diodes is $\mathrm{fc}=$ $18 * 400=7,2 \mathrm{kHz}$. For frequencies lower than fc/2, Fig. 3 clearly shows that the model of the ATRU can be identified by a (Rs,Ls) impedance: $Z(j \omega)=R s+j L s \omega$
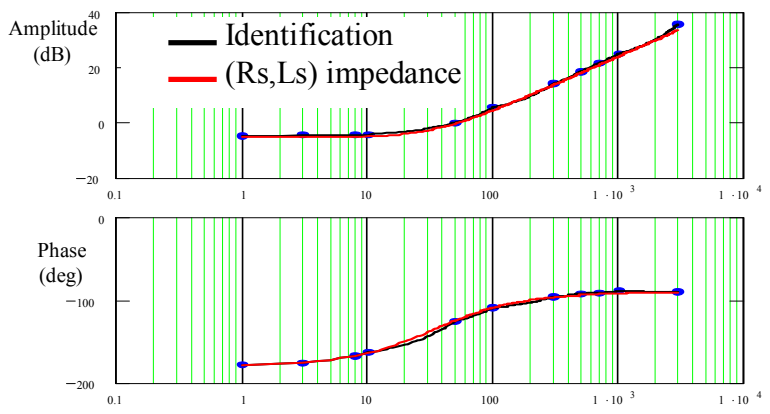

Fig. 6: Frequency domain identification of the ATRU output impedance when supplied by an ideal AC source

Fig. 7 shows the identification results when the control loop is taken into account (case 2). It is shown that the source output impedance can be identified by:

$Z(j \omega)=\frac{K \cdot\left(1+\frac{2 \xi}{\omega_{0}} j \omega+\left(\frac{j \omega}{\omega_{0}}\right)^{2}\right)}{1+T \cdot j \omega}$
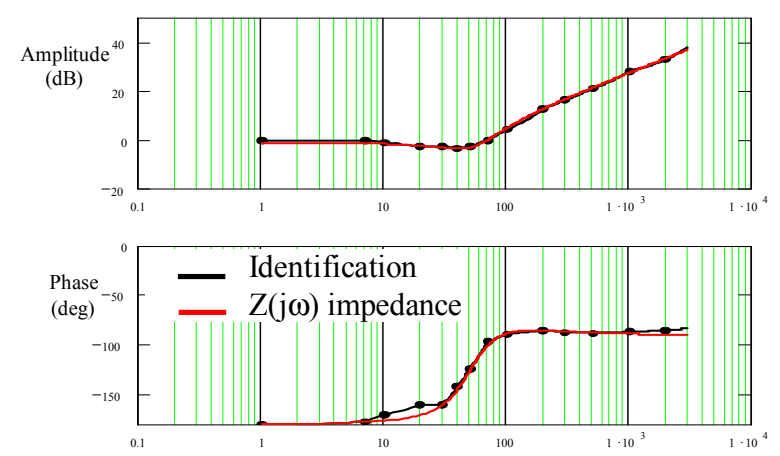

Fig. 7: Frequency domain identification for the ATRU output impedance with non-ideal control loop for the alternator

\section{B. Power channel modeling}

The small-signal equivalent network is then found to be:

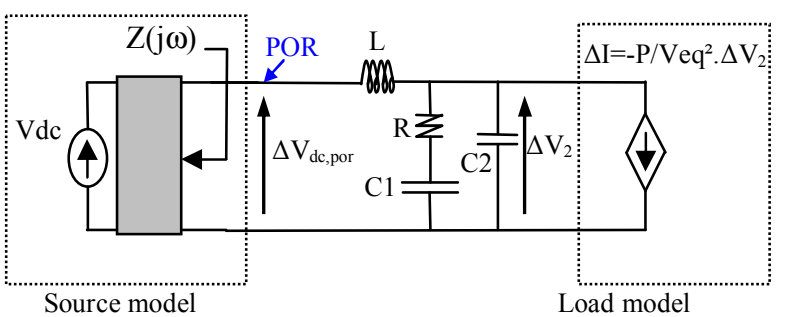

Fig. 8: Small Signal model of the power channel

The model parameters are summed up in Table I.
TABLE I

MODEL PARAMETERS

\begin{tabular}{|c|c|c|c|}
\hline \multirow{5}{*}{$\begin{array}{c}\text { Source } \\
\text { parameters }\end{array}$} & $\begin{array}{l}\text { Case 1: gen. is an } \\
\text { ideal AC source }\end{array}$ & $\begin{array}{l}\mathrm{Rs} \\
\mathrm{Ls}\end{array}$ & $\begin{array}{l}520 \mathrm{~m} \Omega \\
2.5 \mathrm{mH}\end{array}$ \\
\hline & \multirow{4}{*}{$\begin{array}{l}\text { Case } 2 \text { : the gen. } \\
\text { control loops are } \\
\text { taken into account }\end{array}$} & $\zeta$ & 0.6 \\
\hline & & $\omega_{0}$ & $320 \mathrm{rad} / \mathrm{s}$ \\
\hline & & $\mathrm{T}$ & $2.2 \mathrm{~ms}$ \\
\hline & & $\mathrm{K}$ & 0.65 \\
\hline $\begin{array}{c}\text { Load } \\
\text { parameters }\end{array}$ & Power & & \\
\hline \multirow{4}{*}{$\begin{array}{c}\text { DC filter } \\
\text { parameters }\end{array}$} & $\mathrm{L}$ & \multicolumn{2}{|c|}{$20 \mathrm{uH}$} \\
\hline & $\mathrm{R}$ & \multicolumn{2}{|c|}{$1 \Omega$} \\
\hline & $\mathrm{C} 1$ & \multicolumn{2}{|c|}{$4700 \mathrm{uF}$} \\
\hline & $\mathrm{C} 2$ & \multicolumn{2}{|c|}{$400 \mathrm{uF}$} \\
\hline
\end{tabular}

\section{Validation by time domain simulation}

To validate the small-signal modeling and the identification procedure, a power step is applied to the mechanical load driven by the MCU. Results given by the small signal model and SABER time-domain simulations of the power channel are compared. In Fig.9, the voltage at Point of Regulation (POR) after a $+5 \%$ load step is plotted when the alternator is assumed to be an ideal AC source. The same comparison is shown in Fig. 10 when the control loop of the generator is taken into account. In both cases, the small signal models exhibit a good approximation of the time domain simulation.

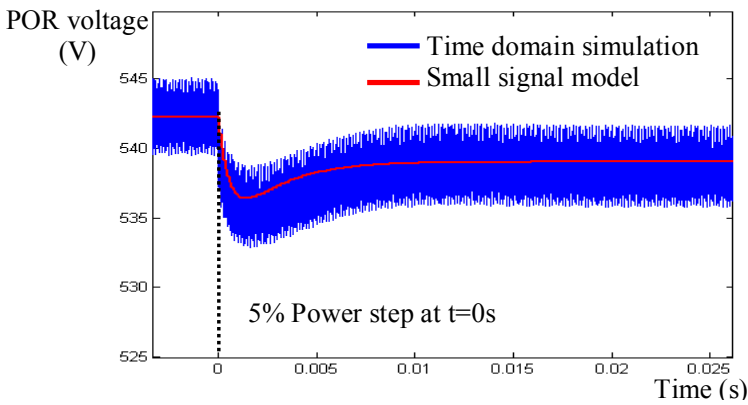

Fig. 9: Time domain validation of the small signal model (Ideal AC source)

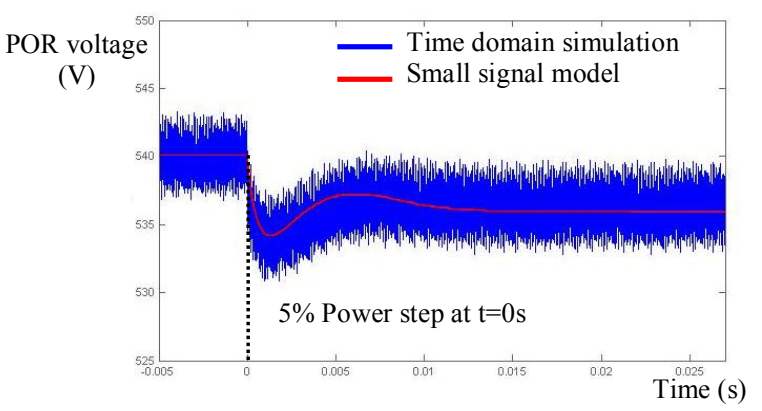

Fig. 10: Time domain validation of the small signal model (generator control loop taken into account) 


\section{ROBUST PERFORMANCE ANALYSIS}

\section{A. Background}

Robustness methods allow the analysis of stability and performance of uncertain systems [7]. The first step is the uncertainties description. Uncertainties are assumed to be norm-bounded around their nominal values and can be classified into two main categories: structured and unstructured uncertainties. Unstructured uncertainties are used to represent unmodeled or neglected dynamics, highfrequency dynamics or time delays for example. Structured uncertainties are parametric uncertainties. They are either complex or real.

An uncertain parameter $\mathrm{U}$ is written by:

$U=U_{\text {nom }} \cdot\left(1+p_{\text {unc }} \delta_{U}\right)$

with: $U_{\text {nom }}$ the nominal value of $\mathrm{U}$

$p_{\text {unc }}$ the relative uncertainty on $\mathrm{U}$

$\delta_{U}$ such that $\left|\delta_{U}\right| \leq 1$.

For a MIMO system, a block-diagonal matrix diagram is used for the system representation as shown in Fig.11. The block diagonal matrix $\Delta \mathrm{i}$ includes the uncertainties. Parametric uncertainties are given by the terms $\left\{\delta_{\mathrm{n}+1} ; \ldots\right.$; $\left.\delta_{\mathrm{n}+\mathrm{m}}\right\}$. Unstructured ones are the $p$ independent full-blocks matrices $\left\{\Delta_{n+m+1}, \Delta_{n+m+2}, \ldots \Delta_{n+m+p}\right\}$. The following matrix representation is then obtained. $\mathrm{P}_{\mathrm{CL}}$ is the system closed-loop matrix (Fig.11):

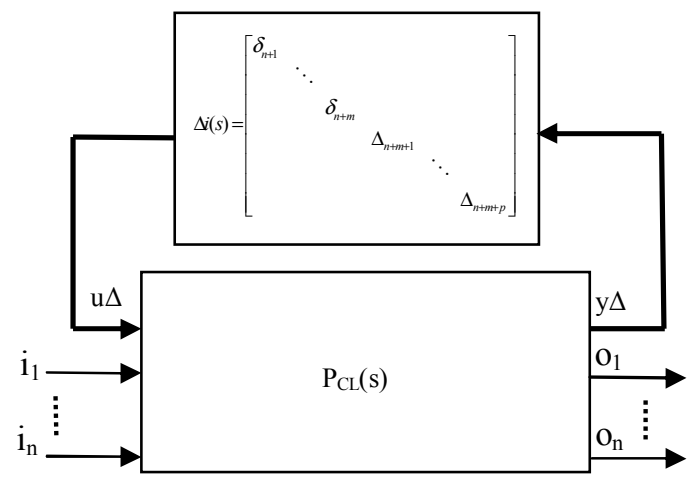

Fig. 11: Matrix representation of the uncertain system

Once the uncertainties are modeled, the desired performance levels have to be fixed. This is done using weighting functions, for example defined as [7]:

$\operatorname{Wperf}(s)=\left(\frac{s / M s+w_{b}}{s+w_{b} \cdot \varepsilon}\right)^{k}$

with: $\varepsilon$ low frequency performance specification $M s$ high frequency performance specification $w_{b}$ desired cut-off frequency.

The $n$ weighting functions are defined for each of the input/output pairs and are linked to $n$ complex fictive uncertainties $\left\{\Delta \mathrm{f}_{1}, \Delta \mathrm{f}_{2}, \ldots \Delta \mathrm{f}_{\mathrm{n}}\right\}$ (Fig. 12). This $\Delta \mathrm{f}$ block is connected to the $\Delta \mathrm{i}$ one to build the $\Delta$ matrix. The so-called $(\mathrm{N}, \Delta)$ representation of the uncertain system is finally obtained, in which the outputs $\mathrm{O}_{\mathrm{wj}}$ of the system are the outputs of Fig. 11, weighted by the Wperf functions.

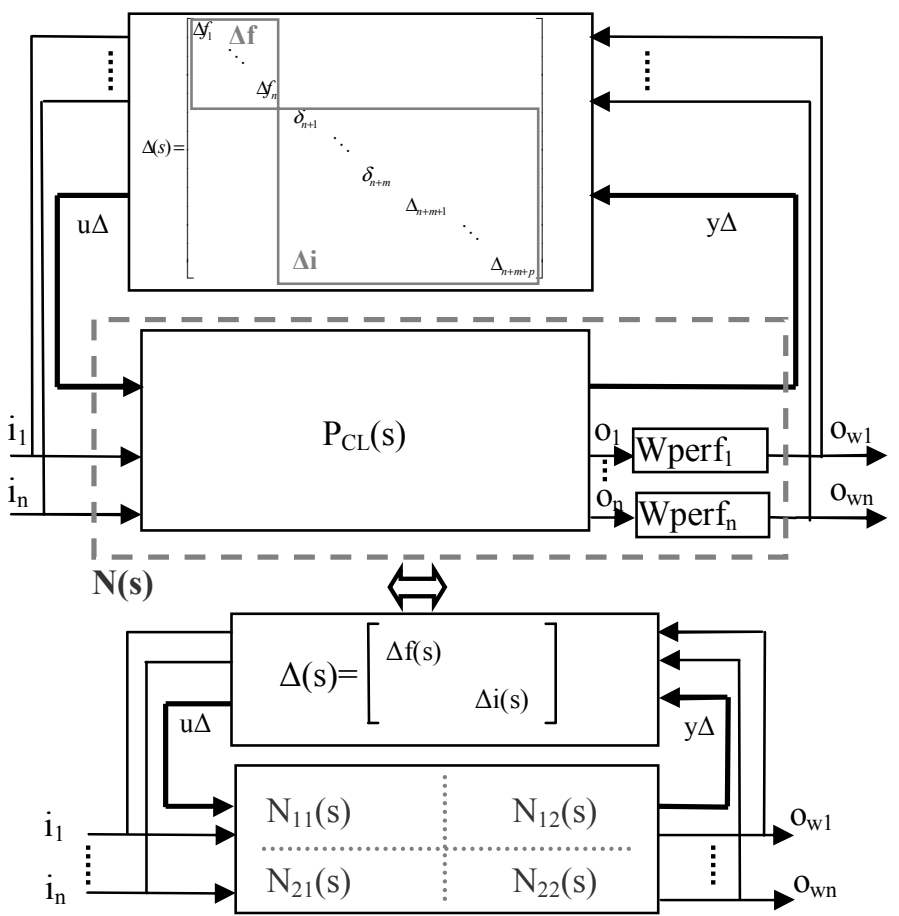

Fig. 12: Matrix representation for Robust Performance Analysis

The structured singular value $\mu_{\Delta}(M(j w)$ defined below allows evaluating the nominal stability (NS), nominal performance (NP), robust stability (RS) and robust performance (RP) of the closed-loop system [7,9]:

$\mu_{\Delta}(M(j w))=\frac{1}{\min _{\Delta}\left(\sigma_{\max }(\Delta) / \operatorname{det}(I-M \Delta)=0\right)}$

$\Delta$ is a stable LTI block-diagonal matrix and $\sigma_{\max }$ the maximum singular value.

NS, NP, RS and RP are then solved following the conditions listed below:

$$
\begin{array}{ll}
N S & \Leftrightarrow \quad \mathrm{N}(\mathrm{s}) \text { is internally stable } \\
N P \Leftrightarrow & \forall \omega \mu_{\Delta f}\left(N_{22}(j \omega)\right)<1 \text { and NS } \\
R S \Leftrightarrow \quad \forall \omega \quad \mu_{\Delta i}\left(N_{11}(j \omega)\right)<1 \text { and NS } \\
R P \Leftrightarrow \quad \forall \omega \quad \mu_{\Delta}(N(j \omega))<1 \text { and NS }
\end{array}
$$

Note that for a given $\Delta$ structure, exact $\mu$ calculation is not possible and a classical approach consists in approximating $\mu$ by lower and upper bounds [7].

\section{B. Application to the power channel}

In the following sections, the robust performance analysis is applied to the power channel. Before presenting the applications developed in section V and VI, the input/output pairs of the system are chosen, the uncertainties are detailed, and the performance specification is explained.

\section{Selection of the Input / Output pairs}

The main objective is to respect the transient envelop given in Fig.2. It means that the DC voltage should not exceed the 
limits given by the standards during load steps. For that purpose and using the notations of Fig.11 and Fig.12, only one input $i_{1}$ (the load power step $\Delta \mathrm{P}$ ) and one output $\mathrm{o}_{1}$ (the resulting voltage response $\Delta \mathrm{V}_{\mathrm{dc} \text {,por }}$ ) are considered.

\section{Uncertainties description}

In the next sections, only real parametric uncertainties on the DC filter parameters are studied. The supposed nominal values are given in Table I. As shown in section $\mathrm{V}$ the uncertainties will be fixed to $40 \%$ on all the DC filter parameters.

\section{Performance specification}

In the time domain, the system performances can be assessed in terms of response time, static error, overshoot and damping. By limiting the maximal gain in the frequency domain, the damping of the time response is improved. The cut-off frequency in the frequency domain tunes the desired response time. This way, equivalencies between desired time domain performances and frequency domain specifications are made (Fig. 13). But this is just an approximation because it is not possible to translate exactly the performances given in Fig.2, defined for any load step value, into small-signal frequency performances. However, by imposing suitable small-signal performances, large-signal standards can be guaranteed.

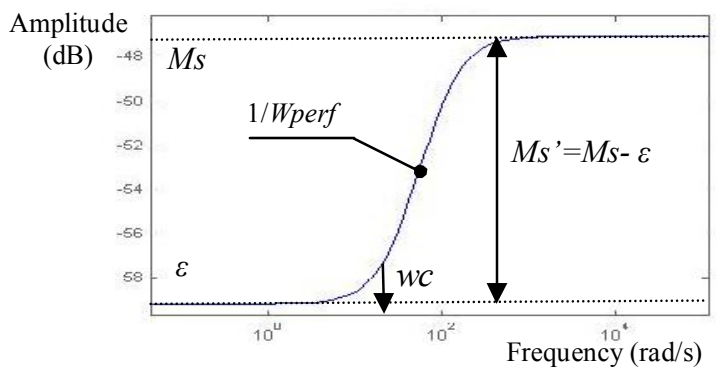

Fig. 13: Template for the transfer function $\Delta \mathrm{V}_{\mathrm{dc}} / \Delta \mathrm{P} 1 /$ Wperf

\section{PERFORMANCE ANALYSIS OF A DEVICE CONNECTED TO AN UNKNOWN NETWORK}

The connection of the source to an unknown network is studied in this section. When designing the source, the supplier does not know the exact values of the power channel parameters. He only knows a supposed nominal value and the parametric uncertainty bounds around this value for all the power channel parameters (DC filter, cables and loads). Similarly, load suppliers do not know the power channel. We will show that a robust performance analysis will enable the designers to respect the standards imposed at the system level by the aircraft manufacturer whatever the power channel parameters values are. Robust performance is first studied when the AC source is assumed to be ideally regulated. Then, the influence of the control loops on devices interactions will be investigated. In this paper, the uncertainties are related to the DC filter. The nominal values are given in Table I and the uncertainty value is $40 \%$ for each parameter.

\section{A. Performance analysis with ideal control loops}

The question is to know whether the system is robust (from a performance point of view) to the modelled parametric uncertainties or not. When the generator is considered as being an ideal 3-phase source (Fig.6 and (1)), the structured singular value bounds are given in Fig. 14:

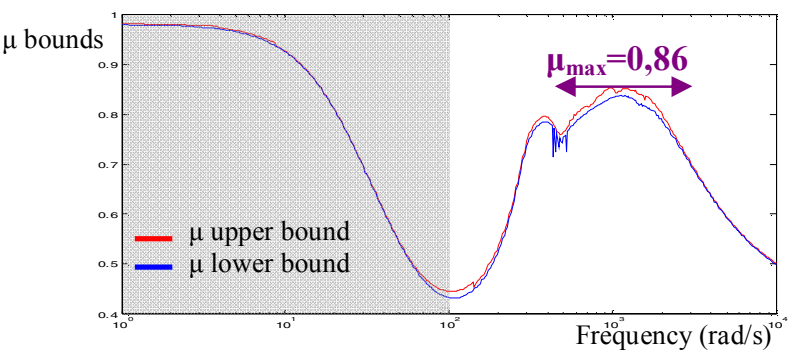

Fig. 14: $\mu$ lower and upper bounds for ideal AC source control

At low frequencies, the $\mu$ calculation is independent of the parametric uncertainty level because the filter parameters are influent only about the cut-off frequency of the filter. That means that any parametric uncertainty value would lead to the same value of $\mu<1$ at low frequencies. Then, only the frequency domain defined by $w>100 \mathrm{rad} / \mathrm{s}$ will be studied (non shaded zone in Fig.14). Outside this domain, the maximum value of the $\mu$ upper bound is 0,86 . This ensures that the condition of (9) is verified and the system performances are guaranteed for any combination of the parameters values inside the parameter space defined by the $40 \%$ uncertainty set.

\section{B. Performance analysis with non-ideal control loops}

The same procedure is now applied to the case of non-ideal voltage control loops. That means that the generator is no more considered as being an ideal voltage source and the source model is given by (2) and Fig.7. A deterioration of the system performances is expected because the generator voltage is no more ideally controlled.

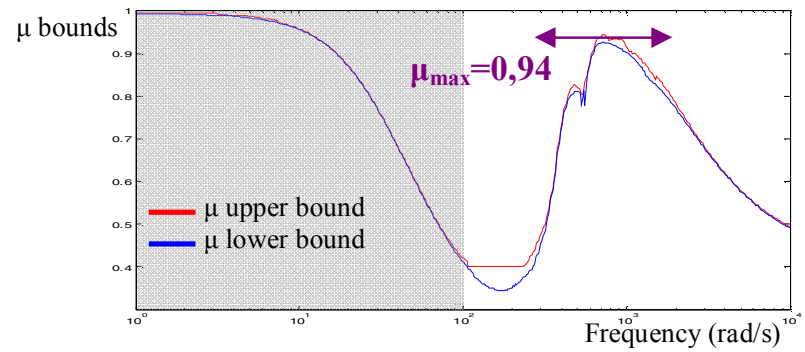

Fig. 15: $\mu$ lower and upper bounds for non-ideal AC source control

The maximum value of the $\mu$ upper bound is $0,94>0,86$ outside the shaded zone. This means that the performances may be deteriorated, by comparison with the ideal control loop case. But it is not as critical as it could have been expected. Indeed, couplings between the AC source control and the DC bus dynamics are not strong. This can be explained by the presence of the ATRU which decouples the $\mathrm{AC}$ source and the DC bus. Indeed, this device is highly inductive because of the autotransformer. If the system was not found to be robust in this study case, it would have been 
necessary to come back over the source control and calculate a more robust controller. As a conclusion, these results show the effectiveness of the method for analysis and design of a source feeding an unknown network.

\section{INFLUENCE OF REQUIRED PERFORMANCES ON WEIGHT}

The influence of the standard on the acceptable uncertainty size is now studied. This size is now considered as being a design margin. The higher this design margin is, the higher the margins are for optimizing the system weight. For illustrating the links between standards and design margins, the non-ideal source model will be considered.

\section{A. Influence of the required response time}

The required response time is tuned by the cut-off frequency of the weighting function. The higher it is, the faster the time-domain response is. Hence, a constant Ms' factor is considered and $w c$ is variable (Fig.13). For each wc value, the design margin is calculated. The results are given in Fig.16. It clearly shows that requiring a cut-off frequency of more than $w c m=2 * 24840 \mathrm{rad} / \mathrm{s}$ (time faster than $20 \mathrm{~ms}$ ) leads to a decrease in design margin. But for $w c<w c m$ the design margins are not increased, which means that degrading the performances of the system may not lead to a gain in weight. These results show that there exists a optimal compromise between response time of the system and its design margins.

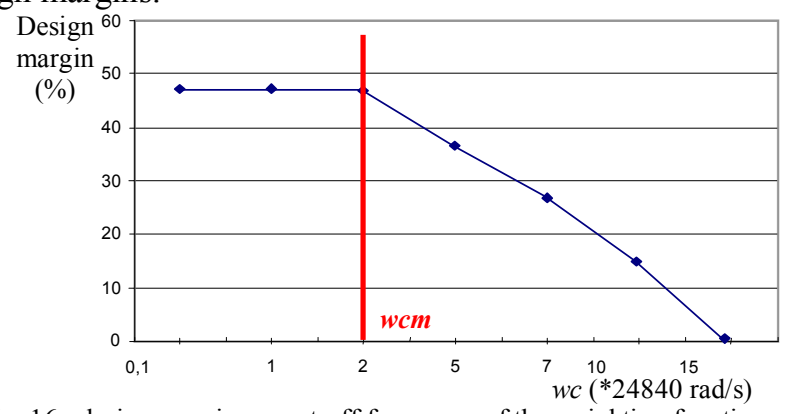

Fig. 16: design margin vs. cut-off frequency of the weighting function

\section{B. Influence of the required overshoot factor}

A similar compromise can be seen from Fig.17 for the overshoot factor. It is tuned by the Ms' factor and the lower $\mathrm{Ms}$ ' is, the lower the design margins are. It means that a system with low overshoots is potentially heavier than a system which tolerates high overshoots.

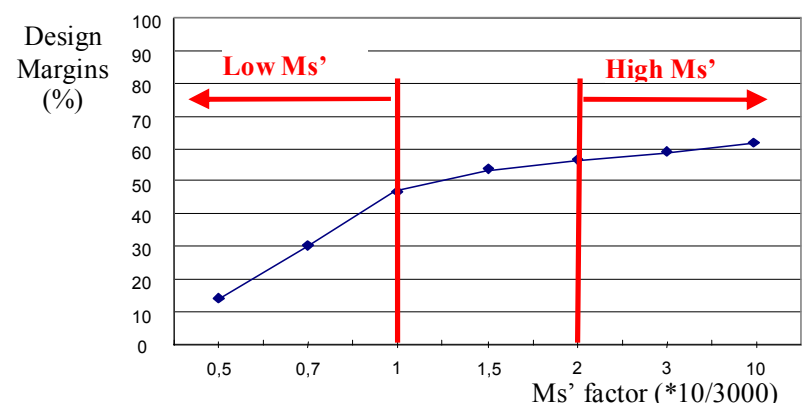

Fig. 17: design margins vs. Ms’ factor of the weighting function
C. Conclusion: influence of required performance on weight

Both previous analyses show that a compromise has to be made between potential weight decrease and performances: deteriorating the required performances does not always mean a gain in the electrical system weight. Even if this study can not be directly used for the definition of HVDC systems standards, it proves the efficiency of robust performance analysis to help the designer for a system level optimization.

\section{CONCLUSION}

In this paper, a robust performance analysis method was described and applied to an aircraft DC power channel. This method was shown to be efficient to solve two key design issues of HVDC networks. The first one was to estimate the robustness of a device before its integration in the network. This integration should be made easier by imposing the source and loads suppliers to be robust to DC network parametric uncertainties. This solution should improve the pre-design phase. Second, the same tool can be used to estimate the design margins towards the required performances. High design margins may allow the designer to optimize the system in terms of weight. The first main prospect of this paper is a method to design and optimize the devices and their control loops to guarantee robust performances while minimizing weight. The authors will focus on optimal robust control techniques in future publications. The second one is to use "robust" standards. This may mean less restrictive norms from a nominal performance point of view, to get larger margins for the system optimization. The standards should also impose "robust" criteria specified by the aircraft manufacturer to guarantee an adequate dynamical behavior at the system level.

\section{ACKNOWLEDGMENT}

This research is being conducted in the frame of the MOET project, a FP6 European Integrated Project. The authors would like to thank MOET partners for model parameters and on board structure definition.

\section{REFERENCES}

[1] J.G. Ciezki, R.W. Ashton, "Selection and Stability issues Associated with a Navy Shipboard DC Zonal Electric Distribution System", IEEE Trans. On Power Delivery, vol.15, NO.2, April 2000

[2] A. Emadi, M. Ehsani, "Aircraft Power systems: Technology, State of the Art, and Future Trends", IEEE AES Systems Magazine, Jan. 2000

[3] M. Ehsani, "On board Power Management", Power Electronics in Tansportation conf., Oct 2004

[4] T. Nord, "Voltage Stability in an Electric Propulsion for Ships", MSc. Thesis of the Royal Institute of Technology, Stockholm, 2006

[5] T. Suntio, "Input Invariance as a Method to Reduce EMI Filter Interactions in Telecom DPS Systems", IEEE INTELEC, Oct. 2003

[6] F. Barruel, A. Caisley, N. Retière, J.L. Schanen, "Stability Approach for Vehicles DC Power Network: Application to Aircraft On-board System", IEEE $36^{\text {th }}$ Power Electronics Spec. Conf., 2005

[7] S. Skogestad, I. Postlethwaite, "Multivariable Feedback Control: Analysis and Design", John Wiley and Sons, 2005.

[8] More Open Electrical Technologies (MOET) project web site, http://www.moetproject.eu

[9] J. Doyle, B. Fancis, A. Tannenbaum "Feedback Control Theory", Macmillan Publ. Co., 1990 